\title{
Effects of mushroom and chicory extracts on the shape, physiology and proteome of the cariogenic bacterium Streptococcus mutans
}

Caterina Signoretto ${ }^{1 *}$, Anna Marchi ${ }^{1}$, Anna Bertoncelli ${ }^{1}$, Gloria Burlacchini ${ }^{1}$, Alberto Milli ${ }^{1}$, Francesco Tessarolo ${ }^{2}$, Iole Caola ${ }^{3}$, Adele Papetti ${ }^{4}$, Carla Pruzzo ${ }^{5}$, Egija Zaura ${ }^{6}$, Peter Lingström ${ }^{7}$, Itzhak Ofek ${ }^{8}$, David A Spratt ${ }^{9}$, Jonathan Pratten ${ }^{9}$, Michael Wilson ${ }^{9}$ and Pietro Canepari ${ }^{1}$

\begin{abstract}
Background: Dental caries is an infectious disease which results from the acidic demineralisation of the tooth enamel and dentine as a consequence of the dental plaque (a microbial biofilm) accumulation. Research showed that several foods contain some components with antibacterial and antiplaque activity. Previous studies indicated antimicrobial and antiplaque activities in a low-molecular-mass (LMM) fraction of extracts from either an edible mushroom (Lentinus edodes) or from Italian red chicory (Cichorium intybus).
\end{abstract}

Methods: We have evaluated the antimicrobial mode of action of these fractions on Streptococcus mutans, the etiological agent of human dental caries. The effects on shape, macromolecular syntheses and cell proteome were analysed.

Results: The best antimicrobial activity has been displayed by the LMM mushroom extract with a bacteriostatic effect. At the MIC of both extracts DNA synthesis was the main macromolecular synthesis inhibited, RNA synthesis was less inhibited than that of DNA and protein synthesis was inhibited only by roughly $50 \%$. The partial inhibition of protein synthesis is compatible with the observed significant increase in cell mass. The increase in these parameters is linked to the morphological alteration with transition from cocci of the untreated control to elongated cells. Interestingly, these modifications were also observed at sub-MIC concentrations. Finally, membrane and cytosol proteome analysis was conducted under LMM mushroom extract treatment in comparison with untreated S. mutans cells. Significant changes were observed for 31 membrane proteins and 20 of the cytosol fractions. The possible role of the changed proteins is discussed.

Conclusions: This report has shown an antibiotic-like mode of action of mushroom and chicory extracts as demonstrated by induced morphogenetic effects and inhibition of specific macromolecular synthesis. This feature as well as the safe use of this extract as result of its natural origin render the LMM both mushroom and chicory extracts suitable for the formulation into products for daily oral hygiene such as mouthwashes or toothpastes.

Keywords: Streptococcus mutans, Dental caries, Anticaries compounds, Food components

\footnotetext{
* Correspondence: caterina.signoretto@univr.it

'Dipartimento di Patologia e Diagnostica - Sezione di Microbiologia,

Università di Verona, Strada Le Grazie 8, 37134, Verona, Italy

Full list of author information is available at the end of the article
} 


\section{Background}

Dental caries is an infectious disease of worldwide importance $[1,2]$. It results from the acidic demineralisation of the tooth enamel and dentine as a consequence of the dental plaque (a microbial biofilm) accumulation $[3,4]$. Streptococcus mutans and Streptococcus sobrinus are considered the main etiological agents of human dental caries due to their efficient colonization of the dental surface, efficient carbohydrate metabolism and lactic acid production (acidogenicity) and aciduricity (i.e. the capability to survive and multiply in acidic environment) $[1,2]$. Although cariogenic streptococci are included among the normal oral microbiota of humans, both diet and inefficient oral hygiene are the trigger for disease initiation and progression [3]. Tooth colonization by $S$. mutans is conventionally subdivided in a sucroseindependent and a sucrose-dependent phase. Initially, several adhesins of the odontopathogenic bacteria interact with the salivary glycoproteins of the acquired pellicle on teeth surface via bivalent cations (mainly $\mathrm{Ca}^{++}$). During the second phase bacteria adhere tightly to tooth surface as a result of the production of exopolysaccharides (glucans) from sucrose by the activity of distinct glucosyl transferases (GTFs) which act sequentially to produce a final, very hydrophobic, glucan called "mutan". This is responsible for the final tight adhesion of bacteria to tooth surface. If dental plaque is allowed to accumulate, mutans streptococci efficiently metabolize sucrose (or sugar polymers such as starch) to produce large amount of lactic acid capable of solubilising the mineral component of the tooth and to initiate the carious process [1,2]. Several preventive strategies can be used to inhibit or slow down the cariogenic process. These range from fluoride administration, typically in toothpastes to strengthen the enamel and dentine (by substituting $\mathrm{Cl}^{-}$for $\mathrm{F}^{-}$) to better resist the acid damage, to reduction in sugar diet or use of sugar substitutes (e.g. sorbitol and aspartame) [1,2]. However, it is generally accepted that lowering the oral bacterial count (i.e. dental plaque removal) is an effective method for preventing caries development. The manual dexterity of many individuals, however, is not very efficient and good oral hygiene is difficult to maintain. In order to compliment the mechanical nature of the cleaning mouthwashes and toothpastes which contain compounds with antimicrobial and antiplaque activities are recommended.

Research performed over the last three decades has shown that, contrary to the popular belief that foods have a negative impact on oral health, several foods contain some components with antibacterial and antiplaque activity for recent reviews see ref. [5,6]. It seems reasonable, thus, to encourage the consumption of such foods and/or incorporate the active compound(s) in functional foods or in cosmetic products for daily oral hygiene [7]. Furthermore, the trend for using "natural" compounds for oral health products instead of those obtained by chemical synthesis is gaining momentum. Previous studies have shown antimicrobial and antiplaque activities in a low-molecular-mass (LMM) fraction of extracts from either an edible mushroom (Lentinus edodes, very popular in Japan and called shiitake) or from Italian red chicory (early Treviso red chicory, an anthocyanic cultivar of Cichorium intybus) [8-10].

In this work we have evaluated in some detail the antimicrobial mode of action of the LMM fractions of mushroom and chicory aqueous extracts on S. mutans, the main etiological agent of human dental caries.

\section{Methods}

\section{Bacterial strains and growth conditions}

S. mutans UA159 was used throughout this study. Cells were grown in brain hearth infusion broth (BHIB) or on brain hearth infusion agar (BHIA) (Oxoid Ltd, Basingstoke, England). Cultures were incubated at $37^{\circ} \mathrm{C}$ in an atmosphere enriched with $5 \% \mathrm{CO}_{2}$. Growth of $S$. mutans in a biofilm structure was allowed on ceramic hydroxyapatite (HA) discs (Clarkson Chromatography Products Inc., South Williamsport, PA, USA). To achieve this, HA discs $(2.5 \mathrm{~mm}$ diameter for SEM or $25 \mathrm{~mm}$ for the other experiments) were coated with sterile human saliva collected from a pool of donors [11]. Each disc was then incubated in $5 \mathrm{ml}$ of BHIB medium spread with a S. mutans culture in a well of a 6-well tissue culture plate $(35 \mathrm{~mm}$ diameter, flat bottom, Sarstedt, Verona, Italy) at $37^{\circ} \mathrm{C}$ in the capnophylic atmosphere. Every day (for a total of three days) culture supernatants were removed by gentle aspiration and replaced with fresh medium. In order to analyse the effects of the test compound, on 3 day old biofilms a suitable concentration of LMM fraction of mushroom extract was added to the growth medium and incubated for additional 3 hours. At the end of each incubation, biofilms were washed three times with sterile distilled water and then fixed with $2.5 \%$ glutaraldehyde in $0.1 \mathrm{M}$ phosphate buffer $\mathrm{pH} 7.2$ for SEM analysis.

\section{LMM fraction of both mushroom and chicory extract}

Frozen Shiitake mushroom was purchased from Asiago Food SpA, Veggiano, Padua, Italy, and red chicory from The Italian Consorzio Radicchio di Treviso, Treviso, Italy. Both mushroom and red chicory juices were prepared by homogenization of frozen fungi and fresh vegetable. To do this, aliquots (400 g) of frozen fungi or aliquots $(500 \mathrm{~g})$ of fresh red chicory, were homogenized for $2 \mathrm{~min}$ and centrifuged for $10 \mathrm{~min}$ at $8,000 \times \mathrm{g}$. Both juices, after separation from the solid part, were filtered on paper filter and then sterilized by ultrafiltration. The LMM fractions (<5,000 Daltons) of both shiitake mushroom and red chicory were prepared by ultrafiltration of 
the respective crude homogenate using the Vivaflow 200 system (Vivascience AG, Hannover, Germany) equipped with a membrane 5,000 MWCO PES for ultradiafiltration, as described elsewhere [8]. About 70 and $50 \%(\mathrm{w} / \mathrm{w})$ of the components originally present in the crude mushroom and chicory homogenates, respectively, were detected in the ultradiafiltrates. The ultradiafiltrates were sterilized using a $0.20 \mu \mathrm{m}$ pore size membrane (Vivascience), then freezedried and stored up to 3 months at $-80^{\circ} \mathrm{C}$. Immediately before use, a sample was rehydrated with sterile distilled water to obtain a $10 \mathrm{x}$ solution and kept at $4^{\circ} \mathrm{C}$ for no longer than a week. The $1 \mathrm{x}$ concentration of the LMM fraction after reconstitution represents the original concentration in the food.

\section{Evaluation of cell growth and viability}

Optical density (O.D.) was measured at $640 \mathrm{~nm}$ wavelength with a Beckman mod. DU 530 spectrophotometer. Total bacteria were counted as cell particles with a Coulter Counter mod ZBI (Coulter Scientific) equipped with a $30 \mu \mathrm{m}$ capillary. Viable cells were determined as colony forming units (CFU) per ml of culture. Suitable dilutions in sterile saline solution of the untreated and treated cultures were plated on BHIA and plates incubated at $37^{\circ} \mathrm{C}$ for 24 hours in the capnophylic atmosphere.

\section{Evaluation of DNA, RNA and protein synthesis}

Aliquots of an exponentially growing culture $(150 \mu \mathrm{l}$, O.D. 0.2 unit) were placed in the wells of a microtitre plate together with $5 \mu \mathrm{Ci}$ of $\left[{ }^{3} \mathrm{H}\right]$ thymidine (spec. act. $>10 \mathrm{Ci} / \mathrm{mmol}$ ) or $\left[{ }^{3} \mathrm{H}\right]$ uridine (spec. act. $>20 \mathrm{Ci} / \mathrm{mmol}$ ) or $\left[{ }^{3} \mathrm{H}\right]$ leucine (spec. act. $50 \mathrm{Ci} / \mathrm{mmol}$, PerkinElmer Life and Analytical Science, Boston, MA, USA). In some wells suitable dilutions of the test compounds were added. Each determination was performed in triplicate. Microtiter plates were incubated at $37^{\circ} \mathrm{C}$ in the capnophylic atmosphere for $60 \mathrm{~min}$. At the end of this time period the culture was overlaid on a Millipore GF/C glass fibre paper soaked in advance with 10\% trichloroacetic acid (TCA) and plunged in a cold 10\% TCA solution. Filters were then washed three times with cold TCA and, finally, twice with acetone. Radioactivity was determined with a Beckman LS 6500 liquid scintillation counter. Three distinct identical experiments were performed.

\section{Scanning electron microscopy (SEM)}

SEM was performed within a week of fixation of the samples. Glutaraldehyde-fixed samples from both planktonic and biofilm cultures were washed three times with phosphate buffer followed by three rinses in distilled water. Specimens were then serially dehydrated in ethanol and subjected to freeze drying, mounted on metal stubs and sputter-coated with gold. Each specimen was viewed with an ESEM FEG XL30 electron microscope (Fei-Philips) at magnifications of $x 5,000$ to $x 40,000$. [12]. Cell length measurement was performed on 150 bacteria per sample at x10,000 magnification by Image J software (http:// rsbweb.nih.gov/ij/index.html). Data handling and curve fitting with a bimodal Gaussian distribution were performed by Microcal Origin 6.0 (Northampton, MA, USA).

\section{Cytoplasmic and membrane protein extraction for proteome analysis}

One litre of an exponentially growing culture of S. mutans UA159 (O.D. 0.8 units) and one litre of a same culture treated for 60 min with $2 x$ mushroom extract were rapidly chilled in ice and immediately centrifuged in a Sorvall RC$5 \mathrm{~B}$ refrigerated centrifuge with a GS-3 rotor $(5,000 \times \mathrm{g}$ for $10 \mathrm{~min})$. Pellets were washed three times with cold $50 \mathrm{mM}$ phosphate buffer (ph 7.2) and cells fragmented with glass beads $(0.10 \mathrm{~mm})$ in a B. Braun Cell Disruptor (B. Braun, Melsungen, Germany) under a continuous $\mathrm{CO}_{2}$ flow to keep the vial refrigerated. Unbroken cells were removed by centrifugation at $2,500 \times \mathrm{g}$ for $10 \mathrm{~min}$ at $4^{\circ} \mathrm{C}$ and supernatant was centrifuged at $30,000 \times \mathrm{g}$ with a type 40 rotor in a Beckman Optima LE-80 K ultracentrifuge (Beckman Coulter, Inc.) for $60 \mathrm{~min}$. Supernatant (cytoplasmic fraction) was removed and pellet (cytoplasmic membrane and cell wall) washed with phosphate buffer and centrifuged as above three times. Cytoplasmic fractions of treated and untreated S. mutans were precipitated with $15 \%$ of trichloroacetic acid (TCA) in ice and resuspended in $1 \mathrm{ml}$ of a solution containing $1 \mathrm{M}$ Tris, $4 \mathrm{M} \mathrm{NaCl}, 2 \%$ cetyl-trimethylammonium bromide (CTAB) and $1 \times$ protease inhibitor cocktail tablet (Complete, Mini; La Roche). Proteins were purified as previously described by Polati et al. [13]. Briefly, nine volumes of double distilled water were added to the supernatants and samples were centrifuged 20,000xg for $10 \mathrm{~min}$ to remove DNA and polysaccharides. Proteins were then precipitated by addition of four volumes of cold acetone and purified by centrifugation at $20000 \times \mathrm{g}$ for $10 \mathrm{~min}$, and by washing the precipitates twice with absolute ethanol and twice with acetone. As far as the membrane proteins were concerned, the extraction from treated and untreated cells was carried out according to Zuobi-Hasona et al. [14]. Membrane pellet was resuspended in $500 \mu \mathrm{l}\left(\mathrm{NH}_{4}\right)$ $\mathrm{HCO}_{3} 50 \mathrm{mM}$ and $3 \mathrm{ml}$ of a 2:1 (v/v) trifluoroethanol/ chloroform mixture were added to the sample which was maintained at $0^{\circ} \mathrm{C}$ for $1 \mathrm{~h}$ vortexing every $5 \mathrm{~min}$ for $10 \mathrm{sec}$ each. The mixture was centrifuged at 10,000xg for $5 \mathrm{~min}$ and the insoluble interphase was removed, and the remaining mixture was dried using an Eppendorf Vacufuge vacuum centrifuge (Eppendorf srl, Milan, Italy). The residue was suspended in a solubilisation buffer consisting of $7 \mathrm{M}$ urea, $2 \mathrm{M}$ tiourea, 4\% CHAPS, $0,5 \%$ ASB14, 2\% Triton X-100, pH 3-10 Ampholyte (Fluka, Buchs SG, Switzerland). Proteins were then precipitated 
by addition of acetone/methanol $8: 1(\mathrm{v} / \mathrm{v})$ and purified by centrifugation at $20000 \times \mathrm{g}$ for $10 \mathrm{~min}$. All the resulting protein pellets, both from cytoplasmic and from membrane fractions, were solubilised with a solution containing $7 \mathrm{M}$ urea, $2 \mathrm{M}$ thiourea, 3\% CHAPS, $20 \mathrm{mM}$ Tris. Then 1\% pH 3-10 Ampholyte was added and samples were centrifuged for $30 \mathrm{~min}$ to remove residual contaminants complexed with ampholytes. Samples were incubated with $5 \mathrm{mM}$ tributyl phosphine and $20 \mathrm{mM}$ acrylamide for $60 \mathrm{~min}$ at room temperature to reduce protein disulphide bonds and alkylate the cysteine thiolic groups. The reaction was blocked by the addition of $10 \mathrm{mM}$ DTT Q and samples were stored at $-80^{\circ} \mathrm{C}$. Protein concentration was evaluated with Bradford assay [15].

\section{Two-dimensional gel electrophoresis (2-DE)}

Protein fractionation by 2-DE was performed by rehydrating seven cm long, $\mathrm{pH}$ 3-10 immobilized $\mathrm{pH}$ gradient strips (IPG; Bio-Rad Laboratories, Hercules, CA, USA) for $6 \mathrm{~h}$ with $150 \mu \mathrm{L}$ of the sample solution containing $800 \mu \mathrm{g}$ of total protein from S. mutans cells. Isoelectric focusing (IEF) was carried out with a Protean IEF Cell (Biorad), with a low initial voltage and then by applying a voltage gradient up to $5,000 \mathrm{~V}$ with a limiting current of $50 \mu \mathrm{A} /$ strip and the temperature was set at $20^{\circ} \mathrm{C}$. For the second dimension, the IPGs strips were equilibrated for $26 \mathrm{~min}$ by rocking in a solution of $6 \mathrm{M}$ urea, 2\% SDS, $20 \%$ glycerol, $375 \mathrm{mM}$ Tris$\mathrm{HCl}, \mathrm{pH}$ 8.8. The IPG strips were then laid on $10-20 \%$ gradient SDS-PAGE with $0.5 \%$ agarose in the cathode buffer (192 mM glycine, $0.1 \%$ SDS and Tris- $\mathrm{HCl}$ to $\mathrm{pH}$ 8.3). The electrophoretic run was performed by setting a current of $5 \mathrm{~mA}$ for each gel for $30 \mathrm{~min}$, then $10 \mathrm{~mA} /$ gel for $1 \mathrm{~h}$, and $20 \mathrm{~mA} /$ gel until the end of the run. During the run the temperature was set at $11^{\circ} \mathrm{C}$. The protein spots were revealed with Sypro Ruby stain (Life Technologies Corporation).

\section{Image analysis}

The image analysis of the 2D gels replicates was performed by PDQuest software (Bio-Rad), version 7.3. Each gel was analyzed for spot detection, background subtraction and protein spot OD intensity quantification. The gel image showing the higher number of spots and the best protein pattern was chosen as a reference template, and spots in a standard gel were then matched across all gels. Spot quantity values were normalized in each gel dividing the raw quantity of each spot by the total quantity of all the spots included in the standard gel. Two distinct differential analyses were performed, one for cytoplasmic proteins and one for membrane fractions. In both the experiments gels were divided in two separated groups (control and treated samples) and, for each protein spot, the average spot quantity value and its variance coefficient in each group were determined. A Student's test was performed in order to compare the two groups and identify sets of proteins that showed a statistically significant difference with a confidence level of 0.05 .

\section{Peptide sequencing by nano HPLC-ESI-MS/MS}

In gel digestion by trypsin was performed, according to Shevchenko et al. [16]. Peptide mixtures were separated by using a nanoflow-HPLC system (Agilent Technologies series 1200, Santa Clara, CA, USA). A sample volume of $10 \mu \mathrm{l}$ was loaded by the autosampler onto a $0.3 \mathrm{~mm}$ fused silica pre-column (75 $\mu \mathrm{m}$ I.D.; $375 \mu \mathrm{m}$ O.D.) at a flow rate of $10 \mu \mathrm{l} / \mathrm{min}$. Sequential elution of peptides was accomplished by using a flow rate of $250 \mathrm{nl} / \mathrm{min}$ and a linear gradient from Solution A (2\% acetonitrile; $0.1 \%$ formic acid) to $50 \%$ of Solution B (98\% acetonitrile; $0.1 \%$ formic acid) in 40 minutes over the pre-column in-line with a homemade $15 \mathrm{~cm}$ resolving column (75 $\mu \mathrm{m}$ I.D.; $375 \mu \mathrm{m}$ O.D.; Zorbax 300-SB C18, Agilent Technologies). Peptides were eluted directly into an ion Trap (model Esquire 6000, Bruker-Daltonics, Bremen, Germany). Capillary voltage was $1.5-2 \mathrm{kV}$ and a dry gas flow rate of $10 \mathrm{~L} / \mathrm{min}$ was used with a temperature of $230^{\circ} \mathrm{C}$. The scan range used was from 300 to $1800 \mathrm{~m} / \mathrm{z}$. Protein identification was performed by searching in the National Center for Biotechnology Information non-redundant database (NCBInr) using the Mascot program (http://www.matrixscience. com). The following parameters were adopted for database searches: complete carbamidomethylation of cysteines and partial oxidation of methionines, peptide Mass Tolerance $\pm 1.2 \mathrm{Da}$, Fragment Mass Tolerance $\pm 0.9 \mathrm{Da}$, missed cleavages 2 . For positive identification, the score of the result of $[-10 \times \log (\mathrm{P})]$ had to be over the significance threshold level $(\mathrm{p}<0.05)$.

\section{Chemicals and reagents}

Unless otherwise specified, chemicals and reagents were purchased from Sigma Aldrich, St. Louis, MO, USA).

\section{Results}

Effects of LMM fractions of both mushroom and chicory extracts on cell growth and viability of S. mutans

Different concentrations of LMM fraction of either mushroom or chicory were tested on cell growth of S. mutans. Figure 1 shows the effects of different concentrations on increase in optical density, cell particle number, and cell viability of $S$. mutans. As far as the LMM fraction of mushroom extract concerned (Figure 1, column A), the concentration of $2 \mathrm{x}$ was the minimum capable of inhibiting cell division of S. mutans as evaluated by cell particle counts, while $1 \mathrm{x}$ allowed a slight increase of the total cell number over the experiment and corresponded to two doublings. On the contrary, both concentrations only partially reduced 


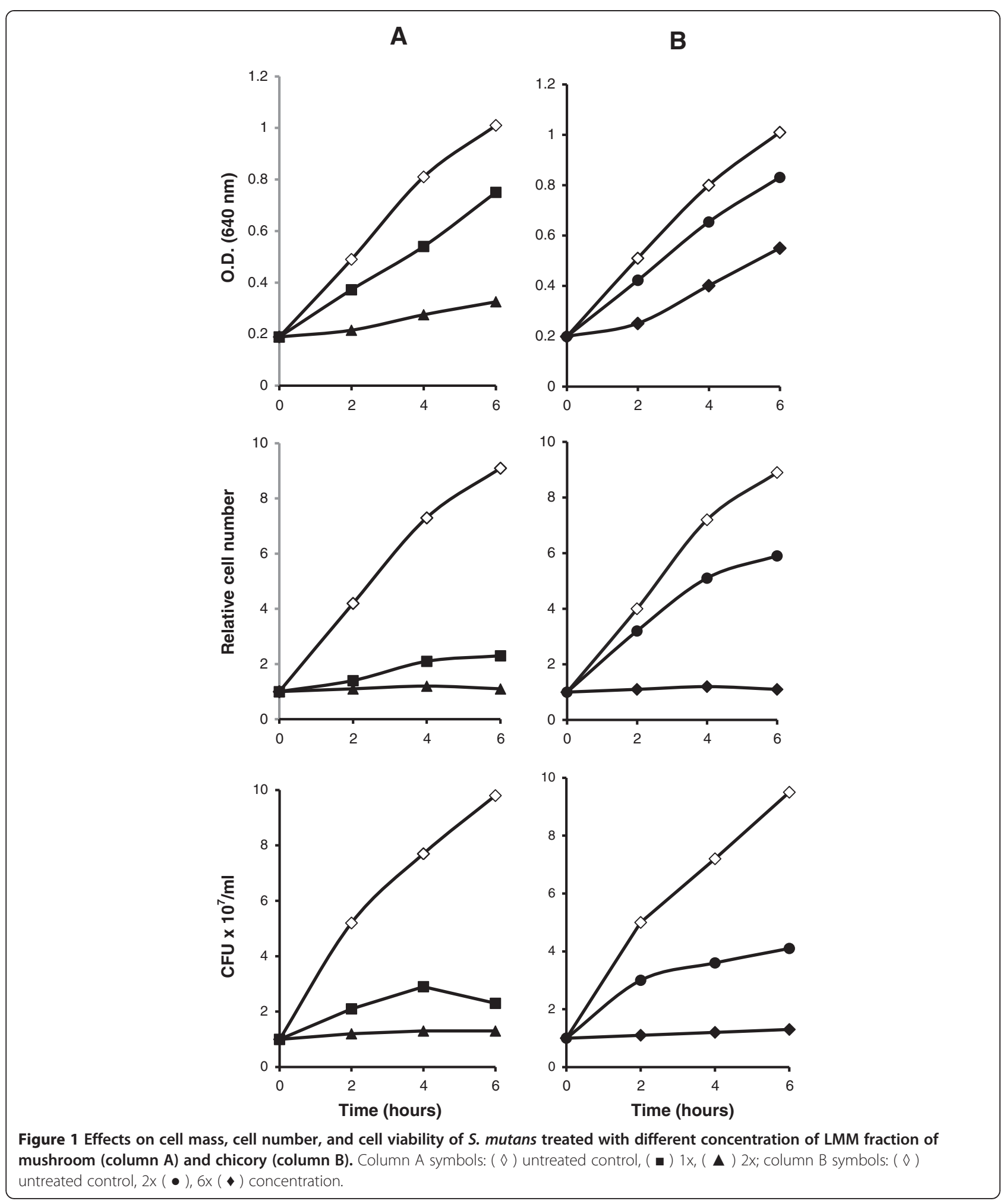

O.D. increase in a dose-dependent manner. Evaluation of cell viability indicated a bacteriostatic effect of the $2 \mathrm{x}$ concentration. Concentrations of LMM fraction of chicory extract were also tested in S. mutans (Figure 1, column B). As compared with LMM fraction of mushroom extract, the $2 x$ concentration was endowed of very limited inhibitory activity. Only $6 x$ concentration was capable of complete inhibition of cell division but without exerting 
bacterial killing. At this concentration a three fold increase in O.D. of the culture was observed.

Effects of LMM fraction of mushroom and chicory extracts on macromolecular synthesis of $S$. mutans

DNA, RNA and protein synthesis of S. mutans were evaluated in the presence of the above reported active concentrations (i.e. the minimal inhibitory and a sub-inhibitory concentration). Table 1 summarises the results: strong inhibitory effect on DNA synthesis was observed during treatment with $2 \mathrm{x}$ or $6 \mathrm{x}$ concentration of mushroom and chicory extracts, respectively, with a residual synthesis lower than $10 \%$ of the untreated control. The $1 \mathrm{x}$ or $2 \mathrm{x}$ subinhibitory concentration of mushroom and chicory extracts, respectively, allowed roughly 24-36\% DNA synthesis. RNA synthesis, albeit to a lesser extent compared with DNA synthesis, was reduced to roughly $20 \%$ of the control in the presence of the inhibitory concentrations and to 34$54 \%$ of the control in the presence of the sub-inhibitory concentration of both mushroom and chicory extracts, respectively. Protein synthesis was inhibited by roughly $50 \%$ in the presence of the inhibitory dose of both mushroom and chicory extracts and to a lesser extent (11-39\%) by sub-inhibitory concentrations.

\section{Morphological examination and cell size distribution of} S. mutans treated with LMM fractions of mushroom and chicory extracts

Bacteria treated as above were also collected for morphological analysis by either optical and scanning electron microscopy. Preliminary observation by optical microscopy showed the presence of elongated cells as a result of the treatment. Thus, we resorted to SEM analysis in order to precisely evaluate cell size and distribution. Figure 2 shows the appearance of $S$. mutans during treatment with $2 \mathrm{x}$ LMM fraction of the mushroom extract. Elongated cells with interrupted septa were seen after a three-hour treatment, while untreated control cells presented the typical

Table 1 Macromolecular synthesis of S. mutans treated for $60 \mathrm{~min}$. with different concentrations of LMM fractions of both mushroom and chicory extracts

\begin{tabular}{lcccc}
\hline LMM fraction & Concentration & \multicolumn{3}{c}{ Macromolecular synthesis } \\
\cline { 3 - 5 } & & DNA & RNA & Protein \\
\hline mushroom & 0 & $100^{b}$ & $100^{b}$ & $100^{b}$ \\
& $1 x^{a}$ & 24 & 34 & 61 \\
chicory & $2 x$ & 8 & 21 & 49 \\
& 0 & $100^{c}$ & $100^{c}$ & $100^{c}$ \\
& $2 x^{a}$ & 36 & 54 & 89 \\
& $6 x$ & 6 & 19 & 44 \\
\hline
\end{tabular}

\footnotetext{
a Subinhibitory dose.

b Control values were: DNA, 287,085 cpm; RNA, 137,216; protein, 9,208.

c Control values were: DNA, 252,718 cpm; RNA, 132,519; protein, 8,749.
}

streptococcal appearance as ovoidal cells. Similar morphological changes were observed during treatment with the $6 \mathrm{x}$ chicory extract as well as with the above reported subinhibitory concentration of both mushroom and chicory (data not shown). Table 2 shows the mean cell length with additional parameters of the treated cells in comparison with the untreated ones. Measures confirmed the morphological changes at the inhibitory concentration, however it is worth of note that elongation has been observed also in cells treated with sub-inhibitory concentrations. Furthermore, analysis of the size distribution of untreated control $S$. mutans cells showed that the characteristic Gaussian bimodal distribution, i.e. just divided single cells and doubled cells prior of dividing, as previously reported for streptococci, was no longer evident in treated cells as a result of global cell elongation (Figure 3).

In a further set of experiments we evaluated the effects of the LMM fraction of mushroom extract on S. mutans biofilm architecture. Figure 4 shows that untreated control biofilm appeared as a compact structure with bacteria close to one another, while in treated biofilm several gaps were observed.

\section{Proteome analysis of S. mutans treated with LMM fraction of mushroom}

Proteome analysis was conducted in both cytoplasmic and membrane fractions of S. mutans. Figure 5 shows a representative separation by 2D-PAGE of the cytosol or membrane proteins of an untreated and a treated S. mutans culture. Several dozen of protein spots that significantly either increased or lowered in treated cells in comparison with those corresponding of the untreated control, were identified after peptide sequencing by nano HPLC-ESI-MS/MS. Only proteins that quantitatively changed \pm 2 fold were considered significantly varied. Table 3 summarises results by grouping the vast majority of the 31 changed membrane proteins on the base of their physiological roles. Interestingly, all (eight) proteins involved in membrane transport significantly decreased, while several other proteins involved in sugar biosynthesis and metabolism, protein biosynthesis and folding, cell cycle and division, aminoacid biosynthesis and metabolism, or miscellanea were either up-regulated or down-regulated in treated $S$. mutans cells. Table 4 summarises results of the study of the cytosol fraction of either control or treated cells. A total of 20 proteins were analysed for their sequence but only one of them remained unidentified. Grouping on the base of their physiological roles have been achieved: $5 / 5$ proteins involved in stress response (e.g. GroEL, GroES, DnaK, SodA, GshR) and 4/4 involved in cell redox homeostasis were all significantly up-regulated, while of the 6 proteins involved in sugar biosynthesis and metabolism 4 were down- and 2 up-regulated, and, finally, 
A
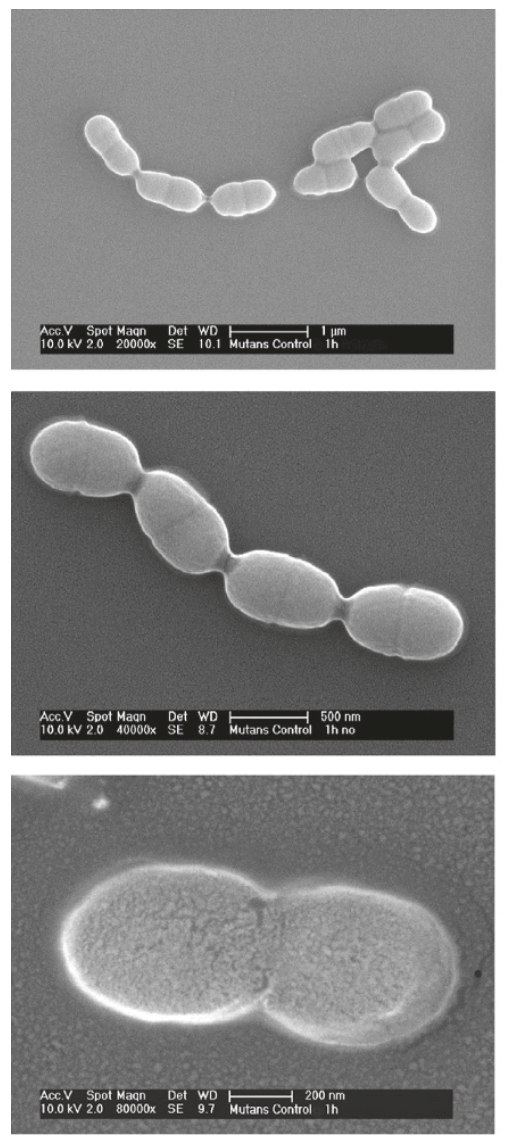

B
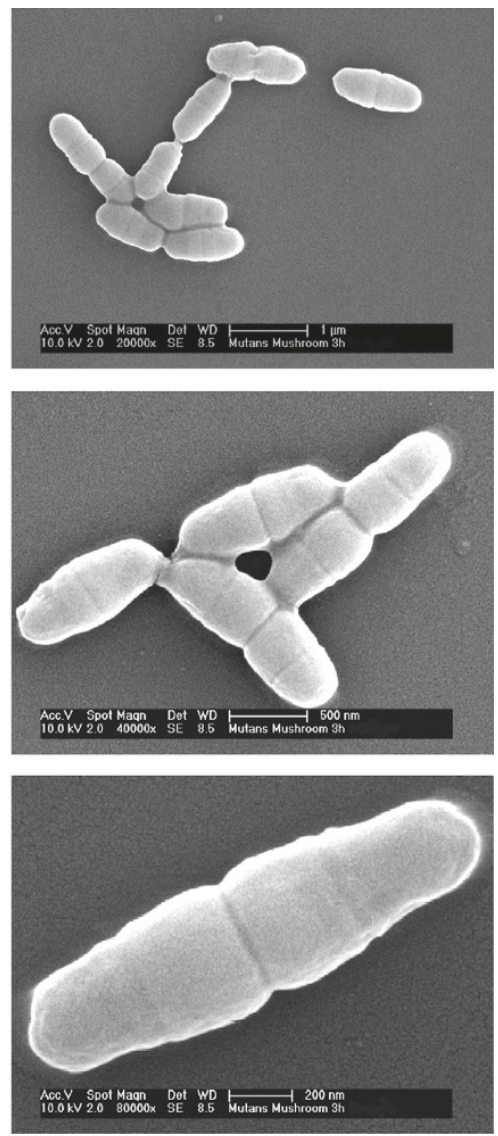

Figure 2 Scanning electron microscopy of untreated S. mutans (column A) and after a three-hour treatment with $2 x$ of LMM fraction of mushroom extract (column B) at different magnifications.

2 proteins were up- and 2 were down-regulated of the 4 proteins involved in protein biosynthesis and folding.

\section{Discussion}

Although foods have to be considered deleterious for oral health in that capable of sustaining growth of oral

Table 2 Cell length measurement of S. mutans cells treated for three hours with different concentrations of LMM fractions of both mushroom or chicory extracts in comparison with control cells at the same time

\begin{tabular}{lllcccc}
\hline Microorganism & $\begin{array}{l}\text { Growth } \\
\text { condition }\end{array}$ & \multicolumn{5}{c}{ Cell length $(\mu \mathrm{m})$} \\
\cline { 3 - 7 } & & Mean & SD & $\begin{array}{c}\text { Min. } \\
\text { value }\end{array}$ & $\begin{array}{c}\text { Max. } \\
\text { value }\end{array}$ & Mode \\
\hline S. mutans & control & 0.78 & 0.16 & 0.48 & 1.28 & 0.59 \\
& Mushroom 1x & & \\
& Mushroom 2x & 0.89 & 0.18 & 0.56 & 1.47 & 0.78 \\
& Chicory 2x & & & & & \\
& & 0.98 & 0.23 & 0.60 & 1.82 & 0.84 \\
& Chicory 6x & 0.95 & 0.23 & 0.60 & 1.60 & 0.82 \\
\hline
\end{tabular}

${ }^{a}$ Subinhibitory dose. bacteria (e.g. sucrose-rich foods and dental caries), however a large number of scientific reports indicates that several commonly consumed foods and beverages of natural origin contain substances with a beneficial impact on oral health $[5-7,17]$. The healthy effects are attributed mainly to the polyphenol fraction which is present in a large number of vegetables [7]. These compounds have been shown to have antimicrobial, antiadhesive, antiplaque activities, thus the consumption of these foods and beverages could be encouraged in order to improve oral hygiene. Epidemiological studies have shown that people consuming foods rich in bioactive compounds have an improved oral health (e.g. tea drinkers have a less risk of dental caries) [5]. Furthermore, attempts to formulate active natural compounds as anticaries and/or antigingivitis oral rinses for daily oral hygiene have shown encouraging results, although a limited number of pilot clinical trials have been performed [5,6,18-22]. Among the numerous foods and drinks tested, the LMM fraction of both shiitake mushroom and red chicory aqueous extract has been previously demonstrated to be 


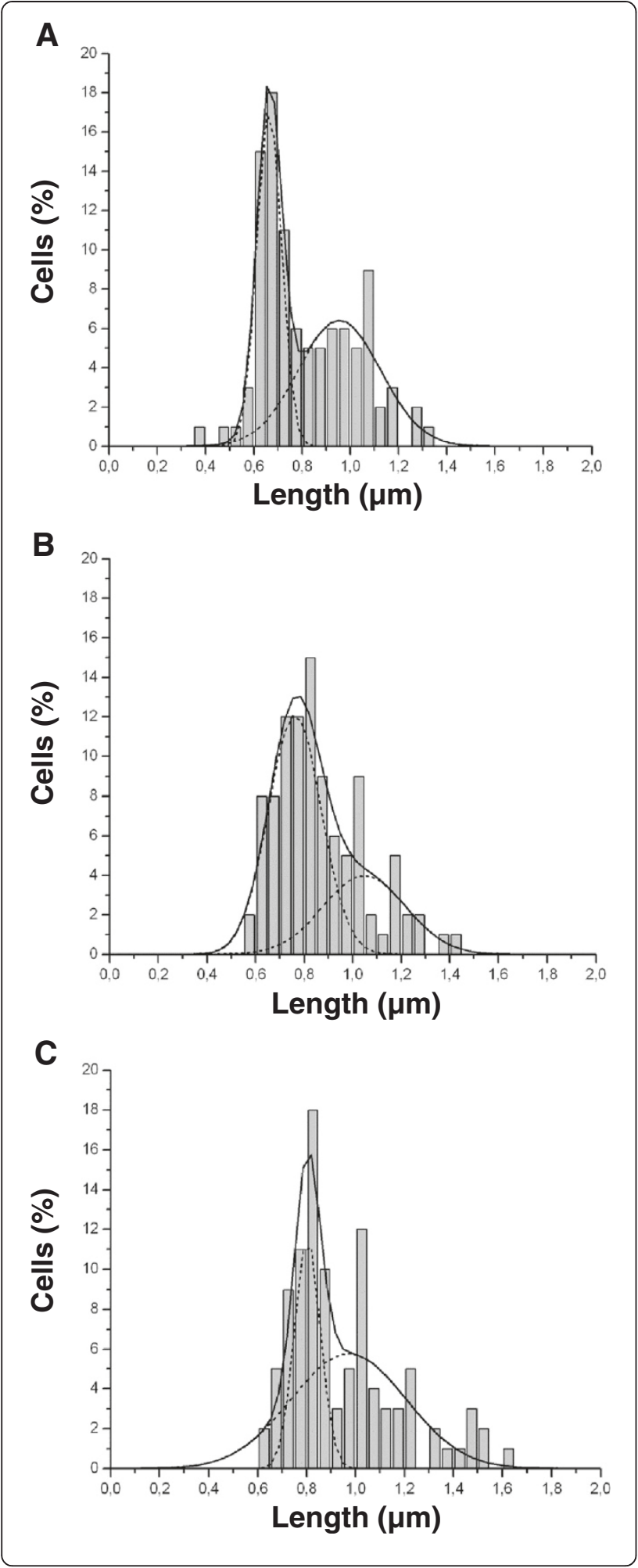

Figure 3 Cell length distribution of S. mutans (A) and after a three-hour treatment with $1 \mathrm{x}$ (B) and 2x (C) LMM fraction of mushroom extract. $X_{1}$ (centre of the first Gaussian fit) values were 0.663 for image $\mathbf{A}, 0.761$ for $\mathbf{B}$ and $0.806 \mu \mathrm{m}$ for $\mathbf{C}_{;} W_{1}$ (width at half maximum of the first Gaussian fit) values were 0.101, 0.218 and $0.126 \mu \mathrm{m}$ for images $\mathbf{A}, \mathbf{B}$ and $\mathbf{C}$, respectively; $\mathbf{X}_{2}$ (centre of the second Gaussian fit) values were 0.955, 1.047 and $0.993 \mu \mathrm{m}$ for images $\mathbf{A}, \mathbf{B}$ and $\mathbf{C}$, respectively; $W_{2}$ (width at half maximum of the second Gaussian fit) values were $0.342,0.342$ and $0.45 \mu \mathrm{m}$ for images $\mathbf{A}, \mathbf{B}$ and $\mathbf{C}$, respectively.

endowed of several antimicrobial features that render them of special interest as components of products for daily oral hygiene $[8-10,21,22]$. In this report we have evaluated the possible mode of action of these extracts on growth, morphology and physiology of S. mutans, the etiological agent of human dental caries. Of the two extracts tested, the best antimicrobial activity has been displayed by the LMM mushroom extract with a minimal
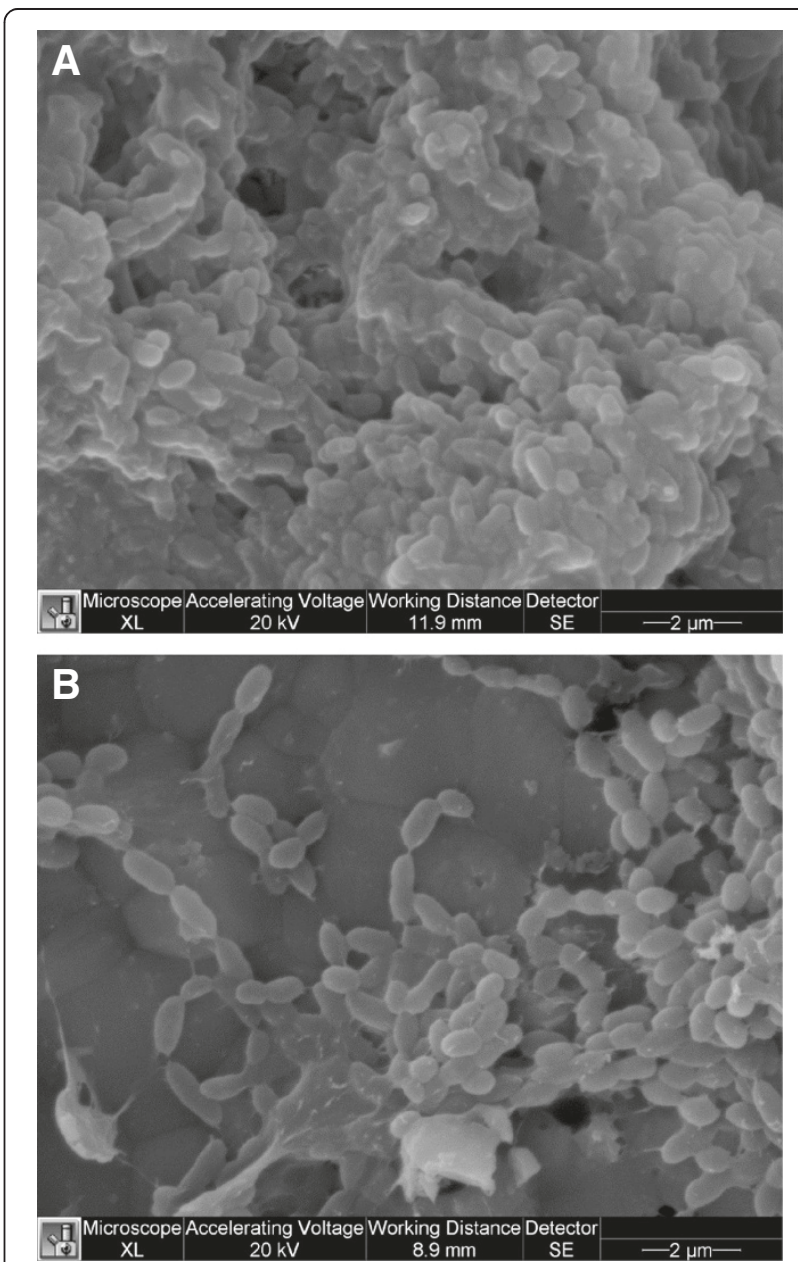

Figure 4 Scanning electron microscopy of $S$. mutans grown in biofilm state (A) and after treatment with $2 x$ LMM fraction of mushroom extract (B). Magnification $\times 12,000$. 

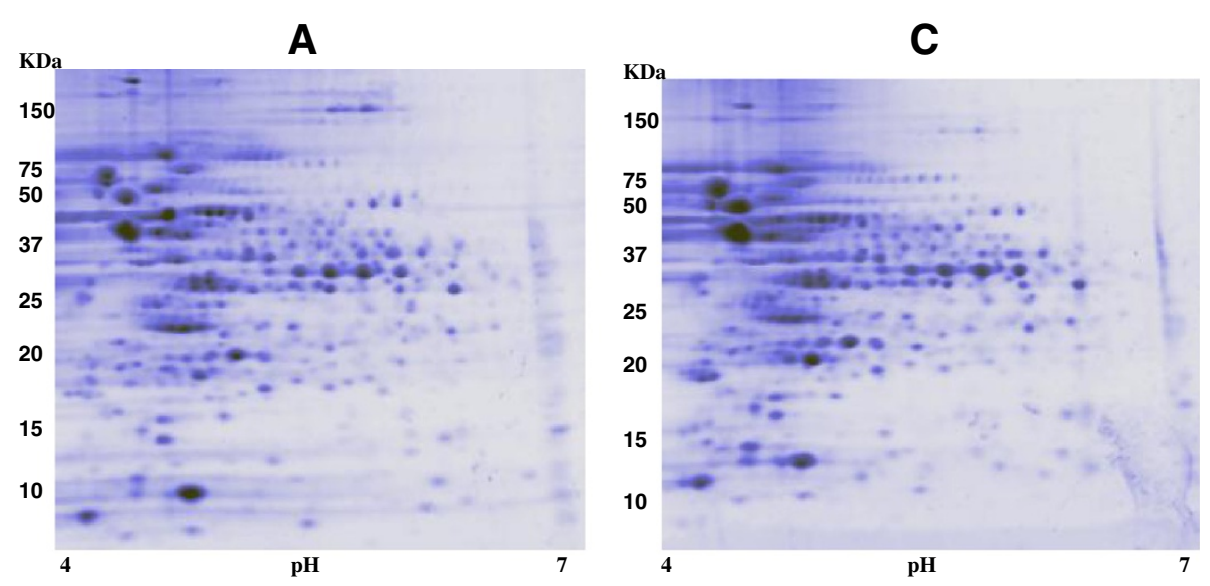

B
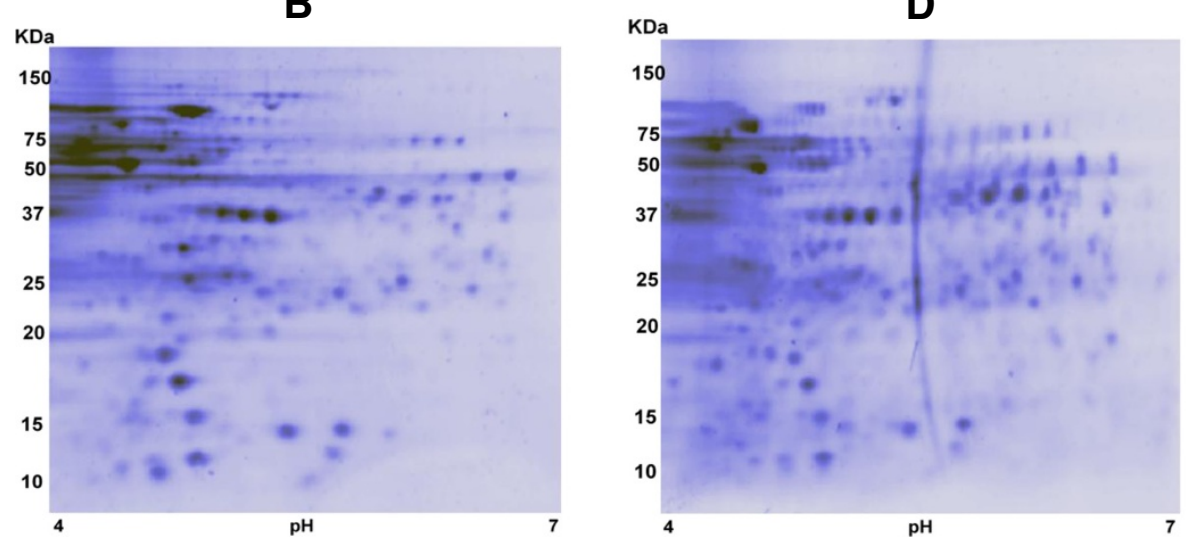

Figure $52 \mathrm{DE}$ cytosol (A) and membrane (C) protein profile of $S$. mutans and after treatment with $2 x \mathrm{LMM}$ fraction of mushroom extract ( $B$ and $D$, respectively).

inhibitory concentration corresponding to $2 \mathrm{x}$ the natural concentration of the vegetable, while the LMM fraction of chicory extract inhibited growth only at $6 x$ concentration. Inhibition of cell division resulted in bacteriostatic effect in both cases. At the minimal inhibitory concentration of both extracts DNA synthesis was the main macromolecular synthesis inhibited, resulting in a residual synthesis less than 10\%, RNA synthesis, although strongly inhibited, was less than that of DNA and, finally protein synthesis was inhibited only by roughly $50 \%$. The residual RNA synthesis and the partial inhibition of protein synthesis is compatible with the observed significant increase in O.D as result of cell mass increase. The increase in these parameters is, in turn, linked to the morphological alteration observed by electron microscopy with transition from cocci or slightly elongated cocci of the untreated control to elongated rods as the consequence of septum synthesis inhibition as effect of the treatment. Analysis of cell size distribution confirms this statement: the typical bimodal distribution of the streptococcal growing control was shifted to higher values when cells elongated. These results are in agreement with the previous observations of the typical mode of cell wall growth and division of streptococci and enterococci $[23,24]$.

The fact that tested natural extracts act by blocking cell division after primary inhibition of DNA synthesis is reminiscent of the chemotherapeutic agents included in the quinolone family [25]. Furthermore, the peculiar response of the macromolecular synthesis and the characteristic morphogenetic effects as a result of the treatment with either mushroom or chicory extracts have also been observed, similarly to quinolones, at sub-inhibitory doses [25]. The morphogenetic effects induced by mushroom or chicory treatment on $S$. mutans cells are indeed similar to those observed in streptococcal thermo-sensitive division mutants when incubated at non-permissive temperature or exposed to both sub- and inhibitory doses of $\beta$-lactam antibiotics [26]. These considerations as a whole lend further support to the hypothesis that the mode of action is comparable to that of antimicrobial families such as quinolones and $\beta$-lactams, thus, an antibiotic-like mode of action is suggested for these compounds $[25,27,28]$. 
Table 3 Identification by nano HPLC-ESI-MS/MS of S. mutans membrane proteins differentially expressed when treated with $2 x$ LMM fraction of mushroom extract

\begin{tabular}{|c|c|c|c|c|c|c|c|c|c|c|}
\hline Protein name & $\begin{array}{l}\text { Spot } \\
\text { no. }\end{array}$ & $\begin{array}{l}\text { Fold of } \\
\text { variation }\end{array}$ & NCBI acc. \# & Gene name & $\begin{array}{l}\text { Theor. Mr. } \\
\text { (Da) }\end{array}$ & Theor. pl & $\begin{array}{l}\text { No. of peptides } \\
\text { identified }\end{array}$ & $\begin{array}{l}\text { Mascot } \\
\text { score a) }\end{array}$ & $\begin{array}{c}\text { Sequence } \\
\text { coverage }^{\text {b) }}(\%)\end{array}$ & Molecular function \\
\hline \multicolumn{11}{|l|}{ MEMBRANE TRANSPORT } \\
\hline F0F1 ATP synthase subunit delta & 2202 & -2.27 & gi|24379920 & $\operatorname{atpH}$ & 20436 & 5.22 & 9 & 528 & 51 & ATPase activity \\
\hline Putative ABC transporter, ATP-binding protein & 5303 & -2.08 & gi|24380277 & psaA & 26297 & 5.58 & 12 & 694 & 57 & ATPase activity \\
\hline $\begin{array}{l}\text { Putative oligopeptide ABC transporter, ATP-binding } \\
\text { protein }\end{array}$ & 5601 & -2.38 & gi|24378766 & oppD & 39147 & 5.47 & 15 & 680 & 56 & ATPase activity \\
\hline Putative sugar ABC transporter, ATP-binding protein & 5804 & -7.32 & gi|24379552 & SMU_1120 & 55575 & 5.78 & 26 & 1197 & 62 & ATPase activity \\
\hline $\begin{array}{l}\text { Putative amino acid ABC transporter, ATP-binding } \\
\text { protein }\end{array}$ & 6406 & -2.56 & gi|24378949 & SMU_461 & 27674 & 5.83 & 19 & 847 & 75 & ATPase activity \\
\hline $\begin{array}{l}\text { Putative amino acid ABC transporter, ATP-binding } \\
\text { protein }\end{array}$ & 7303 & -9.09 & gi|24379380 & SMU_936 & 28340 & 5.90 & 2 & 118 & 10 & ATPase activity \\
\hline $\begin{array}{l}\text { Putative phosphate ABC transporter, ATP-binding } \\
\text { protein }\end{array}$ & 7304 & -2.17 & gi|24379566 & pstB & 30276 & 5.90 & 3 & 136 & 12 & ATP binding \\
\hline $\begin{array}{l}\text { Multiple sugar-binding ABC transporter, ATP-binding } \\
\text { protein }\end{array}$ & 7702 & -2.94 & gi|24379336 & $m s m K$ & 41938 & 5.92 & 14 & 579 & 39 & ATPase activity \\
\hline \multicolumn{11}{|l|}{ SUGAR BIOSYNTHESIS AND METABOLISM } \\
\hline Putative glucose-1-phosphate thymidyltransferase & 2402 & -2.50 & gi|24379858 & $\mathrm{rm} / \mathrm{A}$ & 32275 & 4.90 & 16 & 917 & 53 & Tranferase activity \\
\hline Pyruvate kinase & 4101 & +2.76 & gi|24379618 & pykF & 54333 & 5.09 & 2 & 70 & 5 & Kinase activity \\
\hline Glyceraldehyde-3-phosphate dehydrogenase & 4601 & +2.28 & gi|24378857 & gapC & 36046 & 5.71 & 17 & 725 & 44 & Oxidoreductase activity \\
\hline Galactose 6-P isomerase & 6102 & +3.01 & gi|153674 & lacA & 19025 & 5.80 & 2 & 84 & 15 & Isomerase activity \\
\hline Catabolite control protein A & 8501 & -6.14 & gi|2155300 & $\operatorname{ccp} A$ & 36590 & 7.08 & 3 & 124 & 9 & DNA binding \\
\hline \multicolumn{11}{|l|}{ PROTEIN BIOSYNTHESIS AND FOLDING } \\
\hline $60 \mathrm{kDa}$ chaperonin & 5102 & +2.19 & gi|13898679 & cpn60 & 19827 & 4.53 & 2 & 87 & 14 & Protein binding \\
\hline Phenylalanyl-tRNA synthetase subunit alpha & 6603 & -7.83 & gi|24379902 & phes & 39271 & 5.87 & 14 & 420 & 34 & Nucleotide binding \\
\hline $30 S$ ribosomal protein S8 & 9103 & +2.24 & gi|24380355 & rps $\mathrm{H}$ & 14684 & 9.10 & 7 & 411 & 64 & RNA binding \\
\hline \multicolumn{11}{|l|}{ CELL CYCLE AND DIVISION } \\
\hline Putative Hit-like protein & 2102 & +2.07 & gi|24378905 & SMU_412C & 15560 & 5.13 & 3 & 139 & 30 & Unknown \\
\hline Hypothetical protein SMU.471 & 4002 & -2.04 & gi|24378958 & SMU471 & 12972 & 5.37 & 5 & 255 & 42 & Methylase activity \\
\hline UDP-N-acetylglucosamine 1-carboxyvinyltransferase 1 & 5702 & +2.30 & gi|24379914 & murA1 & 45588 & 5.65 & 10 & 422 & 30 & Tranferase activity \\
\hline \multicolumn{11}{|l|}{ AMINOACIDS BIOSYNTHESIS AND METABOLISM } \\
\hline Uridylate kinase & 3302 & +4.08 & gi|24380005 & pyrH & 26315 & 5.48 & 9 & 460 & 52 & Kinase activity \\
\hline Phospho-2-dehydro-3-deoxyheptonate aldolase & 4505 & +2.60 & gi|24380198 & aroG & 39072 & 6.02 & 8 & 338 & 29 & Lyase activity \\
\hline Shikimate 5-dehydrogenase & 5401 & +2.36 & gi|24379237 & aroE & 31791 & 6.19 & 2 & 106 & 11 & Oxidoreductase activity \\
\hline Putative D-3-phosphoglycerate dehydrogenase & 5604 & -3.33 & gi|24380031 & $\operatorname{ser} A$ & 42771 & 5.56 & 14 & 815 & 51 & Oxidoreductase activity \\
\hline
\end{tabular}


Table 3 Identification by nano HPLC-ESI-MS/MS of S. mutans membrane proteins differentially expressed when treated with $2 x$ LMM fraction of mushroom extract (Continued)

\begin{tabular}{|c|c|c|c|c|c|c|c|c|c|c|}
\hline \multicolumn{11}{|l|}{ MISCELLANEOUS } \\
\hline Putative dihydrolipoamide dehydrogenase & 3603 & +4.23 & gi|24378648 & $a d h D$ & 61708 & 4.88 & 4 & 270 & 10 & Oxidoreductase activity \\
\hline Orotate phosphoribosyltransferase & 4201 & +2.38 & gi|24379645 & pyrE & 22802 & 5.37 & 7 & 381 & 45 & Glycosyltransferase activity \\
\hline Putative exodeoxyribonuclease III & 6403 & -2.56 & gi|24380027 & smnA & 31393 & 5.72 & 11 & 558 & 44 & DNA binding \\
\hline (3R)-hydroxymyristoyl-ACP dehydratase & 7403 & -2.08 & gi|24380109 & $f a b Z$ & 15361 & 8.83 & 3 & 150 & 21 & Lyase activity \\
\hline Not identified & 5301 & +4.52 & & & & & & & & \\
\hline Not identified & 8205 & +2.59 & & & & & & & & \\
\hline Not identified & 8401 & -4.35 & & & & & & & & \\
\hline Not identified & 8506 & +3.30 & & & & & & & & \\
\hline
\end{tabular}

a) Score is $-10^{6} \log (p)$, where $p$ is the probability that the observed match is a random event, based on the NCBI database using the MASCOT searching program as MS/MS data. b) Amino acid sequence coverage for the identified protein. 
Table 4 Identification by nano HPLC-ESI-MS/MS of S. mutans cytosol proteins differentially expressed when treated with $2 x$ LMM fraction of mushroom extract

\begin{tabular}{|c|c|c|c|c|c|c|c|c|c|c|}
\hline Protein name & $\begin{array}{l}\text { Spot } \\
\text { no. }\end{array}$ & $\begin{array}{c}\text { Fold of } \\
\text { variation }\end{array}$ & NCBI acc. \# & Gene name & $\begin{array}{l}\text { Theor. Mr. } \\
\text { (Da) }\end{array}$ & Theor. pl & $\begin{array}{l}\text { No. of peptides } \\
\text { identified }\end{array}$ & $\begin{array}{l}\text { Mascot } \\
\text { score a) }\end{array}$ & $\begin{array}{c}\text { Sequence } \\
\text { coverage }^{\text {b) }}(\%)\end{array}$ & Molecular function \\
\hline \multicolumn{11}{|l|}{ STRESS RESPONSE } \\
\hline 60 kDa chaperonin & 1605 & +2.17 & gi|21666296 & groEL & 56428 & 4.68 & 39 & 2392 & 78 & Protein binding \\
\hline Molecular chaperone dnak & 1706 & +2.29 & gi|24378606 & $d n a k$ & 65246 & 4.58 & 28 & 1265 & 51 & Protein binding \\
\hline 10 kDa chaperonin & 3001 & +3.25 & gi|21666295 & groEs & 10064 & 4.93 & 4 & 273 & 32 & Protein binding \\
\hline Superoxide dismutase & 4108 & +2.60 & gi|24379102 & sodA & 22611 & 4.99 & 9 & 521 & 56 & Ion binding \\
\hline Glutathione reductase & 6607 & +3.89 & gi|4587160 & gshR & 48955 & 5.40 & 3 & 143 & 7 & Oxidoreductase activity \\
\hline \multicolumn{11}{|l|}{ SUGAR BIOSYNTHESIS AND METABOLISM } \\
\hline Glucose-1-phosphate adenylyltransferase & 2501 & -3.57 & gi|92081399 & $\operatorname{glg} C$ & 41906 & 4.72 & 13 & 680 & 38 & Transferase activity \\
\hline Phosphopyruvate hydratase & 2806 & -2.56 & gi|24379669 & eno & 46829 & 4.67 & 14 & 771 & 40 & Lyase activity \\
\hline Putative phosphoglucomutase & 3703 & -12.50 & gi|24379514 & pgm & 63056 & 4.88 & 33 & 1783 & 69 & Transferase activity \\
\hline Tagatose 1,6-diphosphate aldolase 1 & 4303 & -2.17 & gi|153676 & lacD1 & 36468 & 4.96 & 11 & 462 & 31 & Lyase activity \\
\hline $\begin{array}{l}\text { Putative N-acetylglucosamine-6-phosphate } \\
\text { isomerase }\end{array}$ & 6205 & +2.43 & gi|24379109 & SmuNN2025_1351 & 25457 & 5.33 & 7 & 330 & 37 & Deaminase activity \\
\hline Fructose bi-phosphate aldolase & 8001 & +5.24 & gi|4322370 & $f b a$ & 7447 & 8.85 & 3 & 115 & 30 & Lyase activity \\
\hline \multicolumn{11}{|l|}{ PROTEIN BIOSYNTHESIS AND FOLDING } \\
\hline Elongation factor Tu & 1603 & -2.44 & gi|24379182 & tuf & 43891 & 4.84 & 25 & 1257 & 72 & GTPase activity \\
\hline Trigger factor & 1701 & +2.06 & gi|24378614 & tig & 47457 & 4.46 & 20 & 918 & 51 & Isomerase activity \\
\hline 50S ribosomal protein $L 4$ & 3101 & +2.18 & gi|254998187 & SmuNN2025_1762 & 22215 & 9.76 & 6 & 313 & 39 & RNA binding \\
\hline Elongation factor Ts & 3503 & -2.38 & gi|24380373 & tsf & 37695 & 4.91 & 22 & 1218 & 74 & GTP binding \\
\hline \multicolumn{11}{|l|}{ CELL REDOX HOMEOSTASIS } \\
\hline Thiol peroxidase & 0007 & +4.33 & gi|254997527 & $\operatorname{tpx}$ & 17541 & 4.56 & 8 & 450 & 34 & Oxidoreductase activity \\
\hline Alkyl hydroperoxide reductase & 1107 & +12.60 & gi|24379223 & $\operatorname{ahpC}$ & 20465 & 4.57 & 6 & 284 & 34 & Oxidoreductase activity \\
\hline Putative bacterocin transport accessory protein, Bta & 5002 & +2.71 & gi|24380154 & SMU_1788c & 12601 & 5.21 & 2 & 85 & 18 & Oxidoreductase activity \\
\hline Putative glutathione S-transferase & 8202 & +5.64 & gi|24379712 & SMU_1296 & 29973 & 5.74 & 5 & 243 & 16 & Transferase activity \\
\hline Not identified & 8007 & -3.57 & & & & & & & & \\
\hline
\end{tabular}

a) Score is $-10^{6} \log (p)$, where $p$ is the probability that the observed match is a random event, based on the NCBI database using the MASCOT searching program as MS/MS data.

b) Amino acid sequence coverage for the identified protein. 
Analysis of bacterial proteome conducted on separated cytoplasmic fraction from membrane fraction of mushroom treated vs. untreated $S$. mutans cells has showed that eight proteins involved in membrane transport significantly decreased and seven of these were $A B C$ transporters. ABC systems can be divided into three functional categories: (i) importers of nutrients, (ii) exporters including toxins and (iii) members involved in translation of mRNA and DNA repair [29]. Interestingly, we have observed that transport of aminoacids, sugars and phosphate is negatively affected. This, in turns, may cause modification of both sugar and amino acid biosynthesis and metabolism with about half of the involved proteins up-regulated and half down-regulated. Quinolones treatment has been shown to induce expression of $\mathrm{ABC}$ efflux system PatA/Pat B in Streptococcus pneumoniae in order to extrude quinolone molecules from the bacteria cytoplasm [30]. Furthermore the overexpression of this ABC efflux system is associated whit $S$. pneumoniae resistance against quinolones [31]. Our study has not evidenced modification in efflux system during the mushroom treatment, thus suggesting that this cannot represent a biological base for a next acquisition of resistance against the mushroom extract. Protein biosynthesis and folding changes may be consistent with the observed protein synthesis persistence after cell division inhibition. In particular, elongation factors $\mathrm{Tu}$ and $\mathrm{Ts}$ are down-regulated. EF-Tu is activated upon GTP binding and forms a tertiary complex with aminoacylated elongator tRNAs in order to decode the genetic information. This last event triggers GTP hydrolysis and EF$\mathrm{Tu}$ is released from ribosome. EF-Tu is then recycled into the active GTP form by the nucleotide-exchange factor EF-Ts [32]. Down-regulation of EF-Tu and EF-Ts is consistent with $50 \%$ global protein synthesis inhibition as result of treatment.

The cell stress originated during treatment is documented by the significant increase of stress response proteins such as DnaK, SodA, GroES, GroEL and GshR. The heat shock chaperon proteins DnaK, GroEL and GroES bind partially unfolded proteins [33]. These molecular chaperones bind transiently and noncovalently to nascent polypeptides and unfolded or unassembled proteins aiding the protein biogenesis. Superoxide dismutase SodA dismutases superoxide anions which are normally produced within cells and which are toxic to biological systems. Glutatione reductase GshR is important for aerobic growth in order to protect $S$. mutans cells from oxidative stress [34]. Similarly, several proteins involved in cell redox homeostasis are highly overexpressed as effect of mushroom extract treatment. Redox reactions are central to both anabolic and catabolic metabolism and, thus, vital to all organisms. Various molecular sensors continually monitor both internal and external environments adjusting processes involved in maintaining redox homeostasis. In response to redox imbalance, as results of several factors including an increase in oxidation reactions (oxidative stress), new metabolic pathways are initiated and/or systems that protect the cell from further damage are induced [35]. Thus, results from S. mutans proteome analysis, in their whole, are consistent with cell physiology changes in response to mushroom treatment.

\section{Conclusions}

This report has shown an antibiotic-like mode of action of mushroom and chicory extracts as demonstrated by induced morphogenetic effects and inhibition of specific macromolecular synthesis. This feature as well as the safe use of this extract as result of its natural origin render the LMM both mushroom and chicory extracts suitable for the formulation into products for daily oral hygiene such as mouthwashes or toothpastes. Furthermore, encouraging the consumption of this food as well as enriching foods with this bioactive extract may be of great interest particularly in developing countries where economic conditions discourage the use of commercially available products for regular oral hygiene.

\section{Competing interests}

The authors declared that they have no competing interest.

\section{Authors' contributions}

CS and PC equally contributed in experimental design, undertook data analysis and interpretation, and drafted the manuscript. $A M, A B$, and $G B$, carried out basic microbiology experiments. AM carried out 2DE, peptide sequencing by nano HPLC-ESI-MS/MS and data analysis. FT and IC performed SEM analysis and cell size distribution. AP carried out fractionation of plant extracts. CP, EZ, PL, IO, DAS, JP, and MW are part of the Nutrident consortium and aided in the general experimental design. All authors approved the final manuscript.

\section{Acknowledgments}

The research leading to these results has received funding from the European Union's Sixth Framework Programme (FP6) under the contract FOOD-CT-2006-036210 (project NUTRIDENT).

\section{Author details}

'Dipartimento di Patologia e Diagnostica - Sezione di Microbiologia, Università di Verona, Strada Le Grazie 8, 37134, Verona, Italy. ${ }^{2}$ Centro Interdipartimentale di Tecnologie Biomediche (BIOtech), Università di Trento, Via delle Regole 101, 38123, Mattarello, Trento, Italy. ${ }^{3}$ Sezione di Microscopia Elettronica, Dipartimento di Medicina di Laboratorio, APSS, 38100, Trento, Italy. ${ }^{4}$ Dipartimento di Scienze del Farmaco, Università di Pavia, Via Taramelli 12, 27100Pavia, Italy. ${ }^{5}$ DISTAV, Università di Genova, Corso Europa 26, 16132 Genova, Italy. ${ }^{6}$ Department of Preventive Dentistry, Academic Centre for Dentistry Amsterdam (ACTA), Gustav Mahlerlaan 3004, 1081LA, Amsterdam, The Netherlands. ${ }^{7}$ Department of Cariology, Institute of Odontology The Sahlgrenska Academy, University of Gothenburg, Box 450405 30, Gothenburg, Sweden. ${ }^{8}$ Department of Clinical Microbiology and Immunology, Sackler Faculty of Medicine, Tel Aviv University, 39987, Tel Aviv, Israel. ${ }^{9}$ Department of Microbial Diseases, UCL Eastman Dental Institute, 256 Gray's Inn Road, London WC1X 8LD, UK. 


\section{References}

1. Marsh PD, Martin MV: Oral Microbiology. 5th edition. United Kingdom: Churchill Livingstone; 2009

2. Lamont RJ, Burne RA, Lantz MS, Leblanc DJ: Oral Microbiology and Immunology. USA: American Society for Microbiology Press; 2006

3. Newman NH, Wilson M: Dental plaque revisited: oral biofilms in health and diseases. United Kingdom: Bioline; 1999.

4. Marsh PD: Dental plaque: biological significance of a biofilm and community life-style. J Clin Periodontol 2005, 32(suppl 6):7-15.

5. Signoretto C, Canepari P, Pruzzo C, Gazzani G: Anticaries and antiadhesive properties of food constituents and plant extracts and implications for oral health. In Food constituents and oral health: current status and future prospects. Edited by Wilson M. United Kingdom: Woodhead Publishing Limited; 2009:241-262.

6. Signoretto C, Canepari P, Stauder M, Vezzulli L, Pruzzo C: Functional foods and strategies for contrasting bacterial adhesion. Curr Opin Biotechnol 2012, 23:160-167.

7. Cowan MM: Plant products as antimicrobial agents. Clin Microbiol Rev 1999, 12:564-582.

8. Daglia M, Papetti A, Mascherpa D, Grisoli P, Giusto G, Lingström P, Pratten J, Signoretto C, Spratt DA, Wilson M, Zaura E, Gazzani G: Plant and fungal food components with potential activity on the development of microbial oral diseases. J Biomed Biotechnol 2011, 2011:Article ID 274578

9. Spratt DA, Daglia M, Papetti A, Stauder M, O'Donnell D, Ciric L, Tymon A, Repetto B, Signoretto C, Houri-Haddad Y, Feldman M, Steinberg D, Lawton S, Lingström P, Pratten J, Zaura E, Gazzani G, Pruzzo C, Wilson M: Evaluation of plant and fungal extracts for their potential antigingivitis and anticaries activity. J Biomed Biotechnol 2012, 2012:Article ID 510198

10. Zaura E, Buijs MJ, Hoogenkamp MA, Ciric L, Papetti A, Signoretto C, Stauder M, Lingström P, Pratten J, Spratt DA, Wilson M: The effects of fractions from shiitake mushroom on composition and cariogenicity of dental plaque microcosms in an in vitro caries model. J Biomed Biotechnol 2011, 2011:Article ID 135034

11. Tarsi R, Muzzarelli RA, Guzman CA, Pruzzo C: Inhibition of Streptococcus mutans adsorption to hydroxyapatite by low-molecular-weight chitosans. J Dent Res 1997, 76:665-672.

12. Standar K, Kreikemeyer B, Redanz S, Múnter WL, Laue M, Podbielski A: Setup of an in vitro test system for basic studies on biofilm behavior of mixedspecies cultures with dental and periodontal pathogens. PLoS One 2010, 5:e-13135.

13. Polati R, Zapparoli G, Giudici P, Bossi A: CTAB based method for the preparation of total protein extract of wine spoilage microorganisms for proteomic analysis. J Chromatogr B Anal Technol Biomed Life Sci 2009, 877:887-891.

14. Zuobi-Hasona K, Crowley PJ, Hasona A, Bleiweis AS, Brady L: Solubilization of cellular membrane proteins from Streptococcus mutans for twodimensional gel electrophoresis. Electrophoresis 2005, 26:1200-1205.

15. Bradford MM: A rapid and sensitive method for the quantitation of microgram quantities of protein utilizing the principle of protein-dye binding. Anal Biochem 1976, 72:248-254.

16. Shevchenko A, Wilm M, Vorm O, Mann M: Mass spectrometric sequencing of proteins silver-stained polyacrylamide gels. Anal Chem 1996, 68:850-858.

17. Signoretto C, Bianchi F, Burlacchini G, Sivieri F, Spratt D, Canepari P: Drinking habits are associated with changes in the dental plaque microbial community. J Clin Microbiol 2010, 48:347-556.

18. Onisi M, Shimura N, Nakamura C, Sato M: A field test on the caries preventive effect of tea drinking. J Dent Health 1981, 31:13-19.

19. Ooshima T, Minami T, Aonoa W, Tamura Y, Hamada S: Reduction of dental plaque deposition in humans by oolong tea extract. Caries Res 1994, 28:146-149.

20. Weiss El, Kozlovsky A, Steinberg D, Lev-Dor R, Greenstein RBN, Feldman M, Sharon N, Ofek I: A high molecular mass cranberry constituent reduces mutans streptococci level in saliva and inhibits in vitro adhesion to hydroxyapatite. FEMS Microbiol Lett 2004, 232:89-92.

21. Signoretto C, Burlacchini G, Marchi A, Grillenzoni M, Cavalleri G, Ciric L, Lingström P, Pezzati E, Daglia M, Zaura E, Pratten J, Spratt DA, Wilson M, Canepari P: Testing a low molecular mass fraction of a mushroom (Lentinus edodes) extract formulated as an oral rinse in a cohort of volunteers. J Biomed Biotechnol 2011, 2011:Article ID 857987.

22. Lingström L, Zaura E, Hassan H, Buijs MJ, Hedelin P, Pratten J, Spratt D, Daglia M, Karbowiak A, Signoretto C, Rosema M, van der Weijden F, Wilson M:
The anticaries effect of a food extract (shiitake) in a short-term clinical study. J Biomed Biotechnol 2012, 2012:Article ID 217164

23. Edelstein EM, Rosenzweig MS, Daneo-Moore L, Higgins ML: Unit cell hypothesis for Streptococcus faecalis. J Bacteriol 1980, 143:499-505.

24. Glaser D, Higgins ML: Buoyant density, growth rate, and cell cycle in Streptococcus faecium. J Bacteriol 1989, 171:669-673.

25. Higgins P, Fluit AC, Schmitz FJ: Fluoroquinolones: structure and target sites. Curr Drug Targets 2003, 4:181-190.

26. Lleo MM, Canepari P, Satta G: Bacterial cell shape regulation: testing of additional predictions unique to the two-competing-sites model for peptidoglycan assembly and isolation of conditional rod-shaped mutants from some wild-type cocci. J Bacteriol 1990, 172:3758-3771.

27. Spratt BG: Distinct penicillin binding proteins involved in the division, elongation, and shape of Escherichia coli. Proc Natl Acad Sci U S A 1975 72:2999-3003

28. Buijs J, Dofferhoff ASM, Mouton JW, Wagenvoort JHT, Meer JWM: Concentration-dependency of $\beta$-lactam-induced filament formation in Gram-negative bacteria. Clin Microbiol Infect 2008, 14:344-349.

29. Davidson AL, Dassa E, Orelle C, Chen J: Structure, function, and evolution of bacterial ATP-binding cassette systems. Microbiol Mol Biol Rev 2008, 72:317-364.

30. El Garch F, Lismond A, Piddok LJV, Courvalin P, Tulkens PM, Van Bambeke F: Fluoroquinolones induce the expression of pat $A$ and $p a t B$, which encode $A B C$ efflux pumps in Streptococcus pneumoniae. J Antimicrob Chemother 2010, 65:2076-2082.

31. Garvey MI, Baylay AJ, Wong RL, Piddok LJV: Overexpression of patA and pat $B$, which encode $A B C$ transporters, is accociated with fluoroquinolone resistance in clinical isolates of Streptococcus pneumoniae. Antimcrob Agents Chemother 2011, 55:190-196.

32. Andersen $G R$, Nissen $P$, Nyborg AJ: Elongation factors in protein biosynthesis. Trends Biochem Sci 2003, 28:434-441.

33. Craig EA, Gambill BD, Nelson R: Heat shock proteins: molecular chaperones of protein biogenesis. Microbiol Rev 1993, 57:402-414.

34. Yamamoto Y, Kamio Y, Higuki Y: Cloning, nucleotide sequence, and disruption of Streptococcus mutans glutathione reductase gene (gor). Biosci Biotechnol Biochem 1999, 63:1056-1062.

35. Green J, Paget MS: Bacterial redox sensors. Nat Rev Microbiol 2004 2:954-966.

\section{doi:10.1186/1472-6882-13-117}

Cite this article as: Signoretto et al.: Effects of mushroom and chicory extracts on the shape, physiology and proteome of the cariogenic bacterium Streptococcus mutans. BMC Complementary and Alternative Medicine 2013 13:117.

\section{Submit your next manuscript to BioMed Central and take full advantage of:}

- Convenient online submission

- Thorough peer review

- No space constraints or color figure charges

- Immediate publication on acceptance

- Inclusion in PubMed, CAS, Scopus and Google Scholar

- Research which is freely available for redistribution
C Biomed Central 